\title{
Erratum to: Differences in Psychopathology Between Immigrant and Native Adolescents Admitted to a Psychiatric Inpatient Unit
}

\author{
Ana Blázquez • Josefina Castro-Fornieles • \\ Inmaculada Baeza $\cdot$ Astrid Morer • \\ Esteban Martínez $\cdot$ Luisa Lázaro
}

Published online: 4 March 2015

(C) Springer Science+Business Media New York 2015

Erratum to: J Immigrant Minority Health

DOI 10.1007/s10903-014-0143-3

The affiliation of two of the co-authors (Inmaculada Baeza and Astrid Morer) was incorrect in the original publication. The correct affiliation is shown here.

The online version of the original article can be found under doi:10.1007/s10903-014-0143-3.

\footnotetext{
A. Blázquez $(\bowtie) \cdot$ J. Castro-Fornieles · I. Baeza · A. Morer ·

E. Martínez · L. Lázaro

Department of Child and Adolescent Psychiatry and Psychology, Institute of Neurosciences, Hospital Clínic Universitari, C/Villarroel $n^{\circ} 170,08036$ Barcelona, Spain

e-mail: abhinojo@clinic.ub.es

J. Castro-Fornieles · I. Baeza · A. Morer · L. Lázaro

IDIBAPS (Institut d'Investigacions Biomèdiques August

Pi i Sunyer), Barcelona, Spain

J. Castro-Fornieles · L. Lázaro

Department of Psychiatry and Clinical Psychobiology,

University of Barcelona, Barcelona, Spain

J. Castro-Fornieles · I. Baeza · A. Morer · L. Lázaro

CIBERSAM, Barcelona, Spain
} 